\title{
Is it acceptable for medical professionals to kiss paediatric patients?
}

\author{
Yassar Abdullah S Alamri
}

\begin{abstract}
Correspondence to Yassar Abdullah S Alamri, New Zealand Brain Research Institute, 66 Stewart Street, Central Christchurch, Christchurch, Canterbury 8011, New Zealand; yasao@hotmail.com

Received 6 February 2016 Revised 11 April 2016 Accepted 1 May 2016 Published Online First 11 July 2016
\end{abstract}

\section{SLinked}

- http://dx.doi.org/10.1136/ medethics-2016-103619 Ethics 2016;42:636-637.

\section{ABSTRACT}

It is human nature, perhaps more so for doctors and nurses, to comfort children in distress. Unfortunately, however, necessary medical procedures carried out by healthcare providers (eg, venipuncture) can often result in pain and discomfort, which may in turn cause the provider a degree of guilt and distress. Is it ever acceptable to comfort a paediatric patient with a kiss? This essay examines the literature published on this subject reflecting on a recent encounter with a patient.

As a final-year medical student at a major teaching hospital, I was attached to the paediatrics team on the children's surgical ward where we looked after patient A. Patient A was an adorable 18-month-old boy who had been admitted 10 days earlier with ankle osteomyelitis. He required a prolonged course of intravenous antibiotics. Despite his illness, he always had a big grin on his face and constantly waved at us when his dad carried him around the ward.

One day, the paediatric registrar assigned me the difficult task of placing an intravenous cannula in patient A since his previous intravenous line was obstructed. Although I had enjoyed a 100\% success rate in placing intravenous cannulae in children $(n=2)$ up to that point, I was still daunted by the challenging task ahead.

Faced with the inevitable, I summoned all help I could get to ensure success on the first go. I explained to the father what I was about to do. I also enlisted his help to position patient $\mathrm{A}$ and comfort him. I asked the nurse to generously apply the local anaesthetic cream to the backs of his little hands. The student nurse offered to bring his toys and provide distraction.

After gathering all the required equipment, I could delay no further. I anxiously cleaned the back of his hand, which was held in place by his father, and inserted the needle towards the vein which I thought I could palpate. Patient A started to grow uncomfortable, more so from the tense situation than pain (I like to think!). I was still in search of the elusive flashback with no avail. It was not long until patient A started crying and tried to withdraw his hand. I defeatedly called the procedure off, and the nurse placed a fluorescent yellow bandage to his hand. I apologised to the father while trying to console patient $\mathrm{A}$, who was looking at me with his tearful betrayed eyes. In a moment of human instinct, I kissed patient A on the head in an attempt to comfort him and perhaps mend the evil impression he then had of me.
It was not until later that day that I had the chance to reflect on the incident. Inflicting procedure-related pain on patients, especially young ones, is not a particularly pleasant experience for doctors or medical students. ${ }^{1}$ Furthermore, the desire to comfort patients and alleviate their pain is a powerful motivator for doctors to continue to do what they do. It was perhaps a moment of countertransference (ie, 'what if he was my son?'), which compelled me to try to comfort patient $\mathrm{A}$ in the way I did (ie, with a hug and a kiss).

Almost all published literature and medical standards refer to the act of kissing between adults within a sexualised context. For example, Gutheil and Gabbard describe physical contact between the doctor and the patient (including kissing and hugging) to be part of a chain reaction that later eventuates in sexual intercourse. ${ }^{2}$ Moreover, the College of Physicians and Surgeons of British Columbia considers hugging and kissing high-risk behaviours. $^{3}$ The New Zealand Medical Council, on the other hand, has adopted a 'zero tolerance' approach to sexual relationships between doctors and patients since $1994 .{ }^{4}$ These, however, remain guidelines for sexual behaviours between, except in the case of rape, two adults.

The place of a kiss or hug in the child-doctor relationship is less clear-cut, as relevant literature is generally lacking. What little literature is available sheds light on doctors' reactions after being kissed by a child ${ }^{5}$ (including an account by an Australian anaesthetist not dissimilar to my ordeal with patient A). ${ }^{1}$

Hugging or kissing a paediatric patient, on the other hand, seems more culturally influenced than actually regulated by professional practice standards. The only relevant data come from a survey of Argentinian paediatric outpatients and their companions; it found that the majority preferred to be greeted with a kiss on the cheek. ${ }^{6}$ This practice, however, is a culture-bound norm and would be problematic to extrapolate to all other cultures; a kiss on the cheek, while customary in some cultures, can be viewed as odd or even offensive in others.

The question remains as to whether what I did was correct. I still believe it was-only given the circumstances, however; the gesture within this context helped comfort patient A and facilitated maintaining some parental trust (by demonstrating to the father my regret and acknowledgement of my failing), as well as helping me feel better about the situation. 
Medical students and junior doctors are sometimes faced with the predicament of having to perform procedures, their experience with which is inadequate. ${ }^{7}$ To master such skills, they need to be practised-a process which, in addition to sometimes instrumentalising patients as 'practice subjects', 8 also involves (often several) failures. In the case of paediatric patients, the reaction of the parent to the failure itself or the practitioner's attempt to comfort the child ought to be considered carefully.

This experience, although potentially trivial to some, served as a personal reminder to be more mindful during patient interactions. This is especially the case with paediatric patients where the relationship is often a tri-faceted one (ie, doctor-childparent).

As for patient A, he was eventually successfully cannulated by the paediatric registrar. His dad later thanked me for taking the time to explain the procedure to him and for comforting his son after my failed attempt. Patient A continued to improve and continued to smile, and was discharged home a few days later.

Competing interests None declared.
Patient consent Obtained.

Ethics approval New Zealand National Ethics Committee.

Provenance and peer review Not commissioned; externally peer reviewed.

\section{REFERENCES}

1 Mullins GC. The kiss. Med J Aust 2012;197:670.

2 Gutheil TG, Gabbard GO. The concept of boundaries in clinical practice: theoretical and risk-management dimensions. Am J Psychiatry 1993;150:188-96.

3 College of Physicians and Surgeons of British Columbia. Sexual Boundaries in the Patient-Physician Relationship. Professional Standards and Guidelines. 2009 (05/02/ 2016). https://www.cpsbc.ca/files/pdf/

PSG-Sexual-Boundaries-in-the-Patient-Physician-Relationship.pdf

4 Medical Council of New Zealand. Sexual Boundaries in the Doctor-Patient Relationship: a resource for doctors. 2004 (05/02/2016). https://www.mcnz.org.nz/ assets/News-and-Publications/Statements/Importance-of-boundaries.pdf

5 Rosala F. Child psychiatry, the question of a kiss. Soins Psychiatr 2010;270: 27-9.

6 Eymann A, Ortolani M, Moro G, et al. Greeting modalities preferred by patients in pediatric ambulatory setting. Arch Argent Pediatr 2011;109:14-17.

7 Alamri YA. Medical students performing lumbar punctures: are we doing enough? N Z Med J 2012;125:89-93.

8 Le Morvan P, Stock B. Medical learning curves and the Kantian ideal. J Med Ethics 2005;31:513-18. 